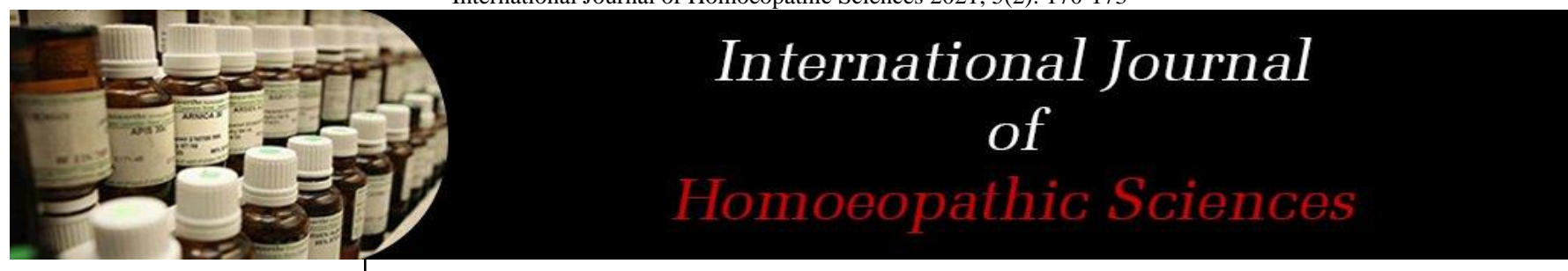

E-ISSN: $2616-4493$

P-ISSN: 2616-4485

www.homoeopathicjournal.com IJHS 2021; 5(2): 170-173

Received: 22-02-2021

Accepted: 24-03-2021

Dr. Jayashree Janagam Assistant Professor,

Department of Psychiatry,

National Homoeopathy

Research Institute in Mental

Health, Kottayam, Kerala,

India

\section{Dr. ND Mohan}

Psychiatrist, HOD and

Professor, Department of

Psychiatry, National

Homoeopathy Research

Institute in Mental Health,

Kottayam, Kerala, India
Corresponding Author: Dr. Jayashree Janagam Assistant Professor, Department of Psychiatry, National Homoeopathy Research Institute in Mental Health, Kottayam, Kerala, India

\title{
A case report of paranoid schizophrenia treated with homoeopathy in psychiatry ward
}

\section{Dr. Jayashree Janagam and Dr. ND Mohan}

DOI: $\underline{\text { https://doi.org/10.33545/26164485.2021.v5.i2c.380 }}$

\begin{abstract}
Paranoid Schizophrenia being the common type of schizophrenia in most parts of the world but the literature available is sparse in homoeopathy. This case report is an attempt to increase the evidencebased studies through homoeopathic intervention in paranoid schizophrenia, treated in the psychiatry ward, without antipsychotic medication. The case was assessed by Brief Psychiatric Rating Scale (BPRS), baseline BPRS score of 86 turned gradually to a subclinical range of 24 in one month. The patient had good relief for the next one year and was functionally well.
\end{abstract}

Keywords: paranoid schizophrenia, individualized homoeopathy, BPRS, stramonium

\section{Introduction}

Schizophrenia refers to a predominant mental disorder, whose causes are unknown and which involves a complex set of disturbances of thinking, perception, affect, and social behavior. So far, no society or culture has been found free from schizophrenia and there is evidence that this puzzling illness represents a serious public health problem ${ }^{[1]}$. It is the most severe form of mental disorders which disables the person and has a worldwide accepted prevalence of about $1 \%$ in the population. It usually starts in adulthood with the likelihood that a person disables for a lifetime ${ }^{[2]}$. It is found in all societies and in all geographic areas, worldwide 2 million new cases appear each year ${ }^{[3]}$.

The paranoid type of schizophrenia is characterized by a less disorganized thought process, preoccupation with delusions or frequent auditory hallucinations, characterized by the presence of delusions of persecutions, reference, jealousy, innocence or grandeur. They are typically tense, angry, fearful, suspicious, guarded, reserved and sometimes hostile, uncooperative or aggressive ${ }^{[4,5]}$. As per the ICD 10 classification of mental and behavioral disorders, paranoid schizophrenia is described under schizophrenia with ICD code F20.0 ${ }^{[6]}$. Homoeopathy can be a useful treatment option in psychiatric cases as it treats the patient holistically taking mind and body into account. A case with paranoid schizophrenia was studied to understand the importance of evidence-based studies in homoeopathy. The Brief Psychiatric Rating Scale (BPRS) the most frequently used instrument for evaluating psychopathology in patients with schizophrenia ${ }^{[7]}$, has been used in this case report for the assessment.

\section{Case report}

Mr. UK, 47 years male patient, a plumber by occupation was brought by the mother to the OPD of National Homeopathy Research Institute in Mental Health (NHRIMH) on $14^{\text {th }}$ November 2019 with irrelevant and continuous self-talk, self-laughing, increased anger, and suspiciousness towards mother, fears that neighbor coming to kill him, always says don't kill me, hearing a male voice, talking about wife and son that they are coming now, always calling police by saying neighbors talking through a computer, and satellite, running away from home, wandering tendency with sleeplessness, poor appetite, and thirst. Complaints started one month back with sleeplessness, use to sleep only for 2-3 hours, consulted a psychiatrist and admitted to private psychiatric hospital for 9 days. The patient's mother couldn't afford the hospital expenses; they took discharge against medical advice, used allopathic medication in the hospital for 9days. After coming home, he ran away from home, wandering tendency started again, managing him at home was difficult so they came to the NHRIMH OPD with the above complaints. 
The patient and his wife use to have constant quarrels at home and got divorced 6 years back, having one son now staying with the wife. He tried to meet his son after the divorce but the wife did not allow him. The patient is now staying with the mother. After the divorce, he gradually started with murmuring and religiosity increased. There was a property related dispute between the patient and brother 10 months back since then he developed a fear towards police, during the quarrel patient became afraid, not able to withstand there, and left from that situation by keeping the mother all alone. No neurotic traits in childhood. His Premorbid personality is very reserved, introverted, fastidious, and religious. The patient had a problem with hard stools and passes alternate days. He had a desire for tea, refreshing things, and an aversion to milk. Thermally he is Hot. Nothing abnormal was detected on the general physical examination.

\section{Mental status examination}

General appearance and behavior: The patient is conscious cooperative with good personal care. Feels sleepy during an interview, tired look often closes his eyes with drooping of upper eyelids. EEC (eye to eye contact): Poor. PMA (Psychomotor activity): decreased. IPR (Interpersonal relationship): poor. Speech: Irrelevant with normal volume, tone, and reaction time. Mood: Anxious. Affect: Inappropriate, Congruent, average range, Labile. Thought: Flow: increased; Form: NAD (flight of ideas, prolixity, circumstantiality, tangentiality, illogicality or irrationality not detected); Content: Delusion of reference, Delusion of persecution, avoided using a mobile phone, says that invalid satellite connection is present, my words are sending via satellite to reach another person (bizzare delusion), thoughts are injected to the ear. Grandiosity - says PM Modi will call him then he will take bath. Auditory hallucination $2 \mathrm{PAH}$ hearing voices of his neighbor. Orientation: To time, place and person is preserved. Memory: Immediate, recent and remote: Adequate. Attention \& concentration: Sustained and maintained. General information \& intelligence: Adequate as per age and education. Abstract thinking: Normally maintained. Judgment: Social judgment and test judgment: Adequate. Insight: absent.

\section{Diagnosis and assessment}

The case was diagnosed as Paranoid Schizophrenia (F20.0) as per ICD-10 by the Consultant Psychiatrist. The patient was assessed for severity of illness using the 18 points brief psychiatric rating scale (BPRS). The outcome was evaluated based ona change in the BPRS Scores i.e. on the $1^{\text {st }}$ day of admission and the time of discharge.

\section{Intervention}

Patient hospitalized at NHRIMH Psychiatry ward. Totality was erected and subjected to Repertorisation in RADAR 10 (synthesis) repertory. Rubrics considered and the repertorial totality may be referred to in Figure no.1. Based on the totality of symptoms a single dose of Stramonium 200 was prescribed and followed by sac lac daily. The medicine which was procured from HOMCO (Kerala State Homoeopathic Pharmacy) was dispensed from the pharmacy of NHRIMH. Stramonium $1 \mathrm{M}$ one dose was given after 9 days, from the very next day onwards the patient reported remarkable improvement in his mental distress, the remedy was allowed to continue its beneficial action and Sac lac was continued for the patient's satisfaction. The patient didn't receive any other medicine or any specific behavioral therapy. Hence the results are attributable to the prescribed medicine.

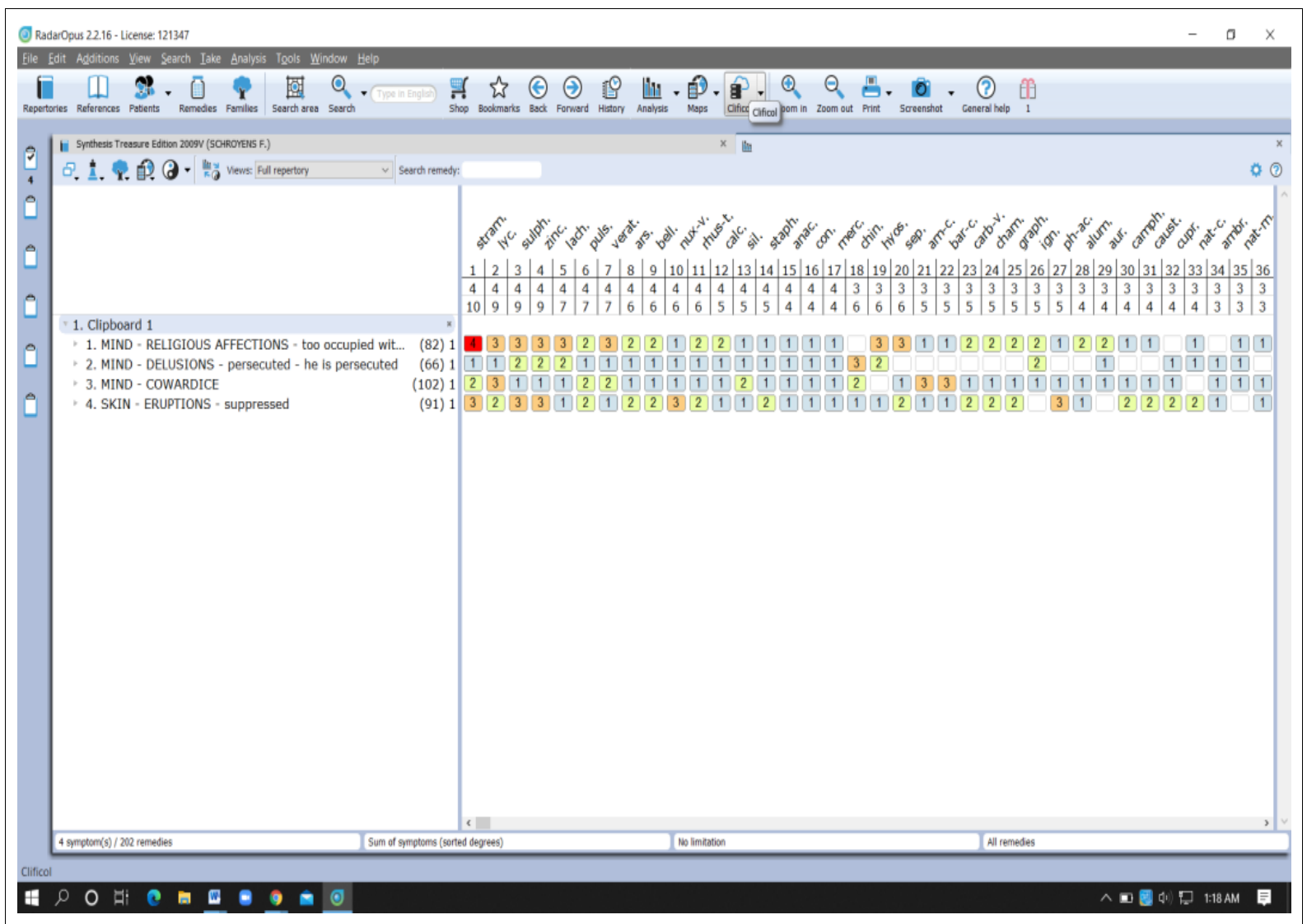

Fig 1: Repertorization chart 


\section{Results}

No homoeopathic aggravation was observed in this case after the administration of medicine. There was a consistent reduction in BPRS score along with general improvement of the patient in the consecutive follow-ups. The observations during follow-up and the corresponding prescriptions are shown in Table 1, BPRS scores in the follow-ups are shown in table 2. After one year of homoeopathic treatment, there was a general improvement and he became functionally well.

Table 1: Follow-up of the case

\begin{tabular}{|c|c|c|}
\hline Date & Observation in the psychiatry ward & Treatment \\
\hline $16 / 11 / 2019$ & $\begin{array}{l}\text { EEC poor, Mood: changeable, Speech: continuous, irrelevant talk, self-talking and laughing, } \\
\text { less sociable, thought broadcasting present, delusion of persecution, hearing voices, says } \\
\text { some device in the head, neighbors are controlling his thoughts. Sleeplessness: only } 3 \text { hours } \\
\text { at night, appetite and thirst improved }\end{array}$ & Stramonium 2001 dose \\
\hline $\begin{array}{l}17 / 11 / 2019 \text { to } \\
24 / 11 / 2019\end{array}$ & $\begin{array}{c}\text { EEC, self-talk and laughing, thought broadcasting, delusion of persecution, hearing voices, } \\
\text { says some device in the head, neighbors are controlling his thoughts still the same. But could } \\
\text { see an improvement in the sleep - the patient started sleeping in the day time. Night sleep: } \\
\text { same. }\end{array}$ & Sac lac \\
\hline $25 / 11 / 2019$ & All observations -SQ & Stramonium 1M 1 dose \\
\hline $\begin{array}{l}26 / 11 / 2019 \text { to } \\
27 / 11 / 2019\end{array}$ & $\begin{array}{c}\text { All observations were the same but there was an improvement in sleep noticed, slept for } 6 \\
\text { hours at night without any disturbances. }\end{array}$ & Sac lac \\
\hline $\begin{array}{c}28 / 11 / 2019 \text { to } \\
01 / 12 / 2019\end{array}$ & $\begin{array}{c}\text { EEC poor, self-talk and laughing >++, } 2 \mathrm{PAH}>++ \text { grandiose talk reduced, anger on mother } \\
\text { still there. Sleep: refreshing }\end{array}$ & Sac lac \\
\hline $02 / 12 / 2019$ & $\begin{array}{l}\text { EEC sporadically started giving, self-talk and laughing nil, delusions and Hallucinations nil } \\
\text { says satellite communication stopped coming since } 2 \text { days, anger towards mother decreased. } \\
\text { Constant praying decreased started mingling with other patients. }\end{array}$ & Sac lac \\
\hline $\begin{array}{c}03 / 12 / 2019 \text { to } \\
12 / 12 / 2019\end{array}$ & Good improvement with no relapse & Sac lac \\
\hline $13 / 12 / 2019$ & Discharged and advised the patient to follow up in OPD once in every month. & $\begin{array}{l}\text { Sac lac daily, Stramonium } \\
1 \mathrm{M} 1 \text { dose SOS }\end{array}$ \\
\hline
\end{tabular}

Table 2: Brief psychiatric rating scale

\begin{tabular}{|c|c|c|c|}
\hline Sr. No. & Symptoms & Scores on admission & Scores on discharge \\
\hline 1 & Somatic Concern & 1 & 1 \\
\hline 2 & Anxiety & 7 & 3 \\
\hline 3 & Emotional withdrawal & 7 & 1 \\
\hline 4 & Conceptual Disorganization & 7 & 1 \\
\hline 5 & Guilty feeling & 1 & 1 \\
\hline 6 & Tension & 7 & 3 \\
\hline 7 & Mannerism and Posturing & 1 & 1 \\
\hline 8 & Grandiosity & 7 & 1 \\
\hline 9 & Depressive mood & 4 & 3 \\
\hline 10 & Hostility & 3 & 1 \\
\hline 11 & Suspicious & 7 & 1 \\
\hline 12 & Hallucinatory Behavior & 7 & 1 \\
\hline 13 & Motor Retardation & 4 & 1 \\
\hline 14 & Uncooperativeness & 4 & 1 \\
\hline 15 & Unusual thought content & 7 & 1 \\
\hline 16 & Blunted affect & 6 & 1 \\
\hline 17 & Heightened emotional tone, agitation, increased reactivity & 4 & 1 \\
\hline 18 & Confusion or lack of proper association for person, place or time. & 2 & 1 \\
\hline & Total score & 86 & 24 \\
\hline
\end{tabular}

\section{Discussion}

Most of the antipsychotic medications cause sedation ${ }^{[8]}$, this can be a causative factor in the increased risk for venous thromboembolism in patients with antipsychotic medication ${ }^{[9]}$. The study by Oberai et al., gives us the positive role of homoeopathic medicines in the management of patients with schizophrenia and the study was conducted on patients who were taking antipsychotic medication ${ }^{[10]}$. In this case, report apart from homoeopathic medication patient didn't receive any other medication and was shown to be effective in the management. Earlier study reflects that homoeopathy can be a good substitute for conventional treatment i.e. an antipsychotic drugs in the treatment of schizophrenia as it does not cause any severe side effects ${ }^{[11]}$.

Patients with schizophrenia often show relapse, and it occurs after the withdrawal of antipsychotic drugs ${ }^{[12]}$. A study on schizophrenia ${ }^{[13]}$, demonstrated that $34.7 \%$ of patients showed relapses within 1 year of the treatment. Another study by Millier et al. ${ }^{[14]}$ showed that symptoms relapsed in around $23.7 \%$ of patients who were given monotherapy and $33.3 \%$ of the patients who were on polypharmacy, symptoms relapsed within 1 year. In this case, the patient followed for more than 1 year and didn't show any relapse, so from this case it is observed that individualized homoeopathic medicine not only manages psychiatric disorders effectively but it is effective in reducing the relapses.

From the day of admission, there was an improvement in Appetite and thirst which can be due to the controlled hospital environment. Slight improvement in sleep was 
noticed after the stramonium 200 but the chief complaints were still the same so the potency increased to $1 \mathrm{M}$. From the very next day, onwards the patient started showing a remarkable improvement and we have assessed the patient's symptoms by using BPRS and the scores came 86 at the baseline i.e. at the time of admission. When we checked after a month of treatment, there was a drastic decrease in the score to 24 has been observed (listed in table 1). This shows the effectiveness of the higher potency in treating psychiatry cases.

In this case, it is convinced that there is ample scope for the utility of Homoeopathic medicines in Psychiatric disorders. To date, very limited research has been published regarding the management of Paranoid Schizophrenia with homoeopathic medicine alone; future studies are suggestible with appropriate study designs.

\section{Conclusion}

This case brings about a piece of evidence for a beneficial effect of homoeopathic medicine in the management of paranoid symptoms through the well-selected potency. The study also reflects the positive role of homoeopathic medicines in the management measured by BPRS. Well planned future research studies with suitable study designs and calculated sample size are necessary to prove the effectiveness of Homoeopathy in Paranoid Schizophrenia.

\section{Acknowledgements}

I would like to thank Dr. K.C. Muraleedharan, Officer-incharge and Dr. R. Sitharthan, Principal, NHRIMH, Kottayam for their support and cooperation.

\section{References}

1. Schizophrenia and public health, Nations for Mental health, WHO. Available on https://www.who.int/mental_health/media/en/55.pdf.

2. Garima Kapoor1, Ravindra Kumar. Case Study: A Work up Case of Paranoid Schizophrenia, The International Journal of Indian Psychology 2018, 6(4). DOI: 10.25215/0604.030 http://www.ijip.in

3. Kaplan and Sadock's pocket handbook of Clinical Psychiatry, 6th edition, publisher Wolters Kluwer 148.

4. Benjamin James Sadock, Virginia Alcott Sadock, Pedro Ruiz. Kaplan \& Sadock's Comprehensive Text Book of Psychiatry, 10th edition, publisher Wolters Kluwer 2017;2:4600.

5. Dr. Bhatia MS, Essentials of Psychiatry, 8th edition, CBS publisher, Delhi 2016, 250.

6. ICD-10 classification of mental and behavioral disorders, clinical description and diagnostic guidelines, WHO, Geneva 80.

7. Leucht S, Kane J, Kissling W, Hamann J, Etschel E, Engel R. Clinical implications of Brief Psychiatric Rating Scale Scores. British Journal of Psychiatry 2005;187(4):366-371. Doi: 10.1192/bjp.187.187.4366

8. Leucht S, Cipriani A, Spineli L et al. Comparative efficacy and tolerability of 15 antipsychotic drugs in schizophrenia: a multiple-treatments meta-analysis. Lancet 2013;382:951-62.

9. Masopust J, Maly R, Valis M. Risk of venous thromboembolism during treatment with antipsychotic agents. Psychiatry ClinNeurosci 2012;66:541-52.

10. Praveen Oberai, Gopinadhan S, Anita Sharma, Chaturbhuja Nayak, Kalpana Gautam. Homoeopathic management of Schizophrenia: A prospective, noncomparative, open-label observational study Central Council for Research in Homoeopathy, New Delhi, India 2016;10(2):108-118.

11. Fisher P, Dantas F, Rampes H. The safety of homoeopathic products. J R Soc Med 2002;95:474-6.

12. Emsley R, Chiliza B, Asmal L, Harvey BH. The nature of relapse in schizophrenia. BMC Psychiatry 2013;13:50.

13. Gumley A, O'Grady M, McNay L, Reilly J, Power K, Norrie J. Early intervention for relapse in schizophrenia: Results of a 12-month randomized controlled trial of cognitive behavioural therapy. Psychol Med 2003;33:419-31.

14. Millier A, Sarlon E, Azorin JM, Boyer L, Aballea S, Auquier $\mathrm{P}$ et al. Relapse according to antipsychotic treatment in schizophrenic patients: A propensityadjusted analysis. BMC Psychiatry 2011;11:24. 